\title{
Correction to: Vector quantile regression and optimal transport, from theory to numerics
}

\section{Guillaume Carlier ${ }^{1,2}$. Victor Chernozhukov ${ }^{3}$. Gwendoline De Bie ${ }^{4}$. Alfred Galichon 5}

Published online: 11 September 2020

○ Springer-Verlag GmbH Germany, part of Springer Nature 2020

\section{Correction to: Empirical Economics https://doi.org/10.1007/s00181-020-01919-y}

The article Vector quantile regression and optimal transport, from theory to numerics, written by Guillaume Carlier, Victor Chernozhukov, Gwendoline De Bie and Alfred Galichon, was originally published electronically on the publisher's internet portal https://link.springer.com/article/10.1007/s00181-020-01919-y on 12 August 2020 with open access. With the author(s)' decision to step back from Open Choice, the copyright of the article changed on 11 September 2020 to (C) Springer-Verlag GmbH Germany, part of Springer Nature 2020, and the article is forthwith distributed under the terms of copyright.

Publisher's Note Springer Nature remains neutral with regard to jurisdictional claims in published maps and institutional affiliations.

The original article can be found online at https://doi.org/10.1007/s00181-020-01919-y.

$凶 \quad$ Alfred Galichon ag133@nyu.edu

Guillaume Carlier carlier@ceremade.dauphine.fr

Victor Chernozhukov vchern@mit.edu

Gwendoline De Bie gwendoline.de.bie@ens.fr

1 CEREMADE, UMR CNRS 7534, PSL, Université Paris IX Dauphine, Pl. de Lattre de Tassigny, 75775 Paris Cedex 16, France

2 MOKAPLAN Inria, Paris, France

3 Department of Economics, MIT, 50 Memorial Drive, E52-361B, Cambridge, MA 02142, USA

4 DMA, ENS, Paris, France

5 Economics and Mathematics Departments, New York University, 70 Washington Square South, New York, NY 10013, USA 